\title{
The identity category: a product and/or a process
}

\section{Kamila Ciepiela}

\author{
University of Łódź, Poland
}

\begin{abstract}
The article focuses on the category of identity and aims to compare and contrast in a cursory manner two major approaches to the issue, namely the one that views identity as a product of the rational mind and the other that expands it to embrace the socio-cultural and interactional milieu. The former sees identity as a category that is constructed as any other object category. The latter posits to move identity to exteriority where it is not only embodied but also negotiated and performed. By drawing on works from the two traditions, the article aims to provide a clearer picture of how the views on the identity construct have changed and developed, by which a conceptually clearer and richer understanding of the issue could have been achieved.
\end{abstract}

Key words: identity, rational, mind, socio-cultural, embodiment, development of identity construct

\section{The concept of identity: introductory remarks}

The concept of identity, seemingly obvious and even tangible to every human being causes a lot of controversy across academic disciplines, even though the research on identity does not have a long history. Taylor (1989) claims that the concept of identity was absent from scholarly investigation before the sixteenth century, and early formulations of the concept were based on philosophical reflection upon the nature of the man and the world-man relationship. Only recently has the topic begun to permeate both academic and everyday discourses, and we have been witnessing a "veritable explosion" in identity talk and research (Block, 2006, p. 34).

The earliest definition of identity as a unified internal phenomenon seems to have its roots in the word's etymology and refers to "the quality or condition of being the same in substance, composition, nature properties, or in particular qualities under consideration; absolute or essential sameness; oneness" (OED, 2002). People, however, are naturally confronted with two paradoxes of their 
identity, namely, (i) of remaining the same person while changing over time, and (ii) of being a whole in face of diversity and fluidity of the external world.

In scholarly reflection and research, these paradoxes are rendered in "an inherent contradiction between a valuing of identity as something so fundamental that it is crucial to personal well-being and collective action, and a theorization of identity that sees it as something constructed, fluid, multiple, impermanent and fragmentary" (Bendle, 2002, p. 2). Some scholars consider identity to be an ascribed category constant across time, but others see it as consisting of many aspects that can and do change over the life course. Larsen-Freeman (2010), following the lines of constructivism, claims that every person is composed of multiple identities that exist in volatile states of construction and reconstruction.

In contemporary literature and research on identity two dominant yet opposing theoretical perspectives are taken. To some scholars identity is an "essential, cognitive, socialised, phenomenological or psychic phenomenon that governs human action" (Benwell \& Stokoe, 2006, p. 3) while to others it is a public phenomenon, a performance or construction that is interpreted by other people.

In this article, a presentation of the essentialist approach to the category of identity explained with Self-categorisation theory and social identity theory will be followed by a presentation of a discursive approach explicated on the example of membership categorisation analysis.

\section{Identity as a mental construct}

Understanding identity as a mental construct descends from Descartes' assertion "I think therefore I am" and is rooted in James's initial conceptualisation of the self (James, 1890/1927) "as a property of the individual, firmly located within the mind and abstracted from experience and interaction with others" (De Fina and Georgakopoulou, 2012, p. 156). This mental representation of oneself can take shape of a prototypical self in the form of an image or a self-schema. Markus (1977) suggests that the self is a concept or a category like any other category and that people form cognitive structures about the self just as they do about other phenomena. Self-schemas, that is, cognitive generalisations about oneself derived from past experiences, organise and direct the processing of information relevant to the self. People hold self-schemas for particular domains; the domains that are personally important, for which they have well-developed self-concepts, and this implies that human identity may be said to be schematic for the domain (Markus, Crane, Bernstein, \& Siladi, 1982). If, for instance, an identity of an expert teacher is considered, three properties in the domain of expertise (knowledge, efficiency, 
creativity) are most frequently used to differentiate expert teachers from trainees (Sternberg \& Horvath, 1995). This identity is constructed on the basis of the information from experience and interaction with others, namely, (1) experts bring knowledge to bear more effectively on problems than do trainees, (2) experts solve problems more efficiently and do more in less time, than do trainees, and (3) experts are more likely to arrive at novel and appropriate solutions to problems than are trainees.

One of the best-known theories of identity as a mental construct is the selfcategorisation theory (SCT) developed by Turner and his colleagues in 1986. The underlying premise behind this theory is that people categorise themselves and others on the basis of the attributes that are particularly salient. When applied to oneself, the process enables a sense of identification with the social category, which results in behaviours and practices that people associate with a particular group. Self-categorisation is an extension of Henri Tajfel and John Turner's (1979) social identity theory of intergroup relations (SIT) which puts more emphasis on motivational and intergroup dimensions. In SCT, grounded in the work on natural categories by Rosch (1978), self-categorisation is driven by perceptual processing of real life data. Turner, however, argues that identity categories are not only conceptual but also verbal, which means that they are used in interactions whereby they are subject to alternations. Moreover SCT posits that identity categories, being psychological structures, also "have a social reality by virtue of their relation to social groups" (Widdicombe, 1998, p. 193). It is also claimed that individuals are born into a society, upon which they are ascribed specific social categories, and with time they develop awareness of these social categories that may become aspects of their self-concept. In this way, identity acquires a real psychological reality and becomes an aspect of the self-concept.

Social categorisation is a cognitive process whose outcome is a construction of schemas that may apply to whole groups, and individuals perceive themselves as either members of the group (ingroup categorisation) or outsiders (outgroup categorisation). Furthermore, "outgroups are more easily and reductively characterised than ingroups, such that ingroup identification often leads to stronger stereotyping and prejudice towards outgroups (Benwell \& Stokoe, 2006, p. 25). Hence "categories operate as domains of exclusion and produce "coercive and regulatory consequences' of their construction" (Cover \& Doak, 2015, p. 548).

Social categorisation serves several psychological goals. First, engaging in social categorisation reduces the cognitive demands placed upon the perceiver. It is cognitively more demanding to interpret each person encountered as an individual rather than a member of one or more social categories. Second, social categorisation serves to enhance our self-concept and boost our self-esteem. Generally, we have the tendency to positively evaluate our ingroup and negatively the outgroup. When the ingroup-outgroup comparison is unfavourable for our ingroup then we aspire 
to change our group membership. This takes us to the third reason why we engage in categorisation, namely, reducing uncertainty regarding our place in the social world. Relying on self-categorisation and social identification, we can engage in planning our future actions, interactions and expectations.

Implicit in SCT is that people can identify simultaneously with multiple groups or adopt different identity representation at different times or under different conditions or emotional states (Roccas \& Brewer, 2002). The process of selfcategorisation opens up a possibility of constructing multiple identification either in parallel, or at various levels of categorisation or serially depending on contexts and emotional states. For example, 'heterosexual' is a higher level identity that includes both 'woman' and 'man,' but in different contexts some other aspects of the categories 'woman' or 'man' like race, class, ethnicity, or nationality can be coinvoked, and emotions may further "colour" the network. In discourses of teaching, for instance, dissatisfied parents can attribute their child's poor classroom behaviour and academic achievement to teacher's young age and their lack of experience or to the teacher's gender as typically females are categorised as caring and nurturing and males as distant and demanding. It shows then, that identity categories form a network of self-schemas that derive from our interpretation of experiences and vary in content and in how elaborate they are. Some are interrelated (teacher and care taker) and others are seemingly separate (teacher and infant). Also, they vary in their temporal focus (past, present, future) and in the extent to which they are congruent with or discrepant from each other. In a way, people are different when they are in different contexts because they make different assumptions about themselves, and they attend to different aspects of what is going on.

Furthermore, as Markus and Nurius (1986) suggest, people may develop different schemas of themselves in view of what they would like to become, they are afraid of becoming and they expect to become. With this the authors point that the content on which identity develops are self-schemas that may differ in longevity and psychological meaningfulness across time and situations (cf. Brewer, 1991; Oyserman, 2007). Hence, identity is not only influenced by current macro- and micro-discourses, but also by those anticipated and future-oriented. Moreover, identity category, just like other object categories, has fuzzy boundaries. "This means that people have a sense that they know what their self is, even though what exactly it refers to differs from situation to situation" (Oyserman et al., 2012, p. 94). People do not always act or behave the same but are essentially the same across spatial and temporal discourses. "This does not imply that identities do not predict behaviours over time but that the predictive power of an identity depends on the stability of the contexts in which it is cued" (Oyserman et al., 2012, p. 93).

From the perspective of SIT, identity categories, pre-discursively organised and activated in social contexts, that is in the presence of other people, always operate to define identity. What is more, being essential, and organised in-advance, 
they cause particular verbal and non-verbal behaviours. For example, being a woman might mean sticking to standard grammar and lexical forms in talk and to standard forms of non-verbal behaviour, because women, playing the social role of mothers and caretakers, are expected to scaffold learning and become models for the younger generation in interactional settings. Identity is based around categorisations which are essentially psychological, subjective individualized mental processes that exert an influence on both thought and overt behaviour.

More recent approaches to self-categorisation predict that identity can be expressed differently in different contexts because of differences in the relative salience of organizing self-concept structures, including individual and collective self-concepts. This means that "which identities come to mind and what they mean in context is a function of both chronic and situational cues, with some situations more likely to cue particular identities or constellations of identities than others" (Oyserman et al., 2012, p. 93). Hence, people's situational identities develop on the basis of the knowledge each individual has acquired and applied to interpret the situational contexts and the pragmatic meaning of these identities in the particular context.

In summary, the mentalist theories maintain that identity construction is mechanical, involuntary, and automatic rather than interactive. Yet, they acknowledge that a person may categorise themselves differently in different situations. What an identity means and, therefore, what is congruent with it, is that it is constructed in the interactional contexts and can motivate different behaviours. Nevertheless, these approaches still "carve the world into a series of finite categories into which their object of study is then moulded and shaped" (Benwell \& Stokoe, 2006, p. 27), that is, identity is treated as fixed, unitary properties of individuals that are intersecting and overlapping, as well as articulated with a range of forms of participation in multiple communities.

\section{Discursive identity}

The shift in viewing identity as a primarily social phenomenon started in 1970s, as a reaction to research on identity in psychology. Within a decade, sociallyoriented approaches blossomed. In 1985, Le Page and Tabouret-Keller published their seminal volume, which was a springboard for sociolinguistic research that relocated identity "from the private realms of cognition and experience, to the public realms of discourse and other semiotic systems of meaning-making" (Benwell \& Stokoe, 2006, p. 4).

Non-essentialist approaches to the problem of identity claim that discourse is constitutive in identity creation, that is, identity cannot exist prior to discourse 
and language; it is constructed and performed with language in interactions with people, institutions and cultures. As Bucholtz and Hall note,

[...] identity inheres in actions, not in people. As the product of situated social action, identities may shift and recombine to meet new circumstances. This dynamic perspective contrasts with the traditional view of identities as unitary and enduring psychological states or social categories (Bucholtz \& Hall, 2003, p. 376)

Such a view of identity enables a researcher to not only see "an 'essential', cognitive, socialised, phenomenological or psychic phenomenon that governs human action" (Benwell \& Stokoe, 2006, p. 4), but also to see how versions of identity are accomplished, disputed, imposed, resisted, managed and negotiated in discourse. Researchers, then, can and should "investigate the micro details of identity as it is shaped from moment to moment in interaction" (Bucholtz \& Hall, 2005, p. 591). Therefore, rather than treating identity as an objective, pre-given fact, they regard it a sum of concerted social achievements that occur in everyday life in varied interactional contexts. At the most fundamental level identity formation lies in our everyday activity, both linguistic and non-linguistic, as well as conscious and unconscious.

Not only do we create ourselves when we are thinking about who we are, but we also create ourselves through our everyday actions and how we live our lives. Orsatti and Riemer (2015, p. 8) following Schatzki (1996, p. 58) argue that "our acting in the world and so our identity formation is unreflective in the sense that conscious thinking or deliberation does not precede or accompany it." Therefore, identity-making can be explained by employing a practice-oriented lens. Practice (Lave \& Wenger, 1991) is not "replicative but a generative activity" which involves "the whole person acting in the world" (p. 49) "not only a relation to specific activities, but a relation to social communities - it implies becoming a full participant, a member, a kind of person" (p. 53).

In other words, in discursive approaches, our identity is not determined by our self-concepts but by how we live our lives unreflectively, when we engage in everyday activities. We actively construct social reality non-verbally and we collaboratively make social order happen in the unfolding sequences of talk. Hence, our identity formation is neither seated in our mind nor is it accomplished through reasoning, but it is embedded and achieved in our practices.

Amongst the multiple theoretical frameworks that see identity as a discursive project collaboratively accomplished in interaction, Membership Categorisation Analysis (MCA) developed by Sacks $(1972 ; 1974 ; 1984 ; 1992)$, seems to be most influential and inspiring. 
Sacks rather than "pursuing research that sought to categorise people into groups so as to predict behaviour, was interested in how people use and deploy ideas and notions of aggregated behaviours as they go about their routine business" (Housley \& Fitzgerald, 2015, p. 3). In this sense, he did not perceive categories as mental schemas expressed explicitly in language but as practices that allow for making rich inferences (Stokoe, 2003) about "the knowledge that members of a society have about the society" (Sacks, 1992, p. 40). Consequently, Sacks did not focus on "observing that people mention social categories in the course of their interaction," rather he sought "the unique configuration of categories and their associated predicates and attributes through which social categories were deployed in any particular instance" (Housley \& Fitzgerald, 2015, p. 4). He assumed that every category carries a set of activities, predicates and obligations that are associated with the category, yet, only some of the features are made interactionally salient, that is relevant for a given performance. Giving the example of "The baby cried, the mommy picked it up," Sacks (1972) explained that we understand the 'mommy' as the 'baby's mommy' because we can hear the categories, 'mommy' and 'baby' as belonging to one constellation of categories - family. We may say that picking up their babies is a category bound activity of mommies, something mommies are expected to do. Categories, then, in addition to being explicit labels, are inferential resources by which people interpret past or present conduct or predict the future behaviour, because they "are conventionally associated with activities, attributes, motives and so on" (Widdicombe, 1998, p. 53). In other words, to find attributions that are made relevant for each category, we need to look for the activities associated with each of the categories. Attributions may be explicitly pronounced or just hinted at, "indicating the subtlety and delicacy of much implicit categorisation membership work" (Baker, 2004, p. 174).

Categories are also "duplicatively organised" (Stokoe, 2003, p. 278) and bound to a wide range of characteristics. Concurrently to 'picking up babies,' 'mommies' are conceived as being of a certain age, having certain kinds of knowledge, and so forth. Categories often come together in paired relationships that Sacks called Standardised Relational Pairs (SRPs), such as 'mommy' and 'daddy', 'husband' and 'wife', 'teacher' and 'learner,' each with duties and obligations in relation to the other. So 'mommy' and 'baby' go together as part of the same family whereby 'mommies' take care of 'babies' rather than the opposite.

In interaction, the deployment of specific category labels becomes an effective way of indicating who does and who does not count as legitimate members of that category according to a current speaker, which in turn, may validate or not current interactional behaviour. Edwards writes, 
By selecting one rather than another [identity category], speakers can perform and manage various kinds of interactionally sensitive business, including their motives and reasons for doing things and saying things. ... As always, for both persons and situations, if they did not have to be described that way (or described at all), then the way they are described can be examined for what it might specifically be doing. (Edwards, 1998, p. 19)

Because interactants orient to local identity categories rather than to dominant discourse categories, identity emerges as an in situ category through the temporary roles and orientations assumed by participants, such as, interviewer, joke teller, evaluator or engaged listener. Analysing what people are doing when they talk reveals that they assign categories to themselves and to others, and these categories are not only mental concepts but also verbal, that is, they can be aligned with specific lexical forms to further stipulate and modify relevant identifications in local contexts. The focus of MCA is on peoples' routine methods of social categorisation practices in local contexts that show how identities emerge, are exercised and performed

\section{Conclusion}

The aim of the article has been to present two contrastive views on the issue of categorisation in identity construction. By drawing on works from two traditions, cognitivist and socio-pragmatic, the author intends to provide a clearer picture of how the views on the identity construct have changed and developed, by which a conceptually clearer and richer understanding of the issue could have been achieved.

In the chronologically earlier essentialist view, identity is argued to develop on the pre-existing, stable core - self-concept - and denotes who a person is. Framed in opposition to this is the discursive approach that views identity categories as emerging in the vicinity of others whereby they shape and are shaped by social practices. Identity categories are also recognised and deployed actively by people who live their lives in various contexts, and by others acting in the world.

In other words, the essentialist approach looks at how we experience an 'I' and how it impacts our behaviours, whereas the non-essentialist view looks at how we become 'someone' in various contexts by making use of social practices. While both approaches recognise the omnirelevance of identity categories, it is only the discursive approach that acknowledges the relevance of these categories for the participants. What matters is how the membership categories emerge through performing certain category-specific actions. 
This article is by no means exhaustive as far as the research on the identity category is concerned. Ever since the term 'identity' was elevated to a theoretical concept, it has been given many interpretations. Nonetheless, it is striking that they all seem to refer to a common underlying concept of recognition. Therefore, the article reviews the two key approaches to the issue so as to invite a return to its basic understandings grounded in human intuition and stipulated in language.

\section{References}

Baker, C. D. (2004). Membership categorisation and interview accounts. In D. Silverman (ed.), Qualitative Research. Theory, Method and Practice, (pp. 162-176). London: Sage.

Bendle, M. (2002). The crisis of 'identity' in high modernity. British Journal of Sociology, 53 (1), $1-18$.

Benwell, B., and Stokoe, E. (2006). Discourse and Identity. Edinburgh: Edinburgh University Press.

Block, D. (2006). Identity in applied linguistics. In T. Omoniyi \& G. White (eds.), The Sociolinguistics of Identity, (pp. 34-49). London: Routledge.

Brewer, M. B. (1991). The social self: On being the same and different at the same time. Personality and Social Psychology Bulletin, 17, 475-482.

Bucholtz, M., \& Hall, K. (2005). Identity and interaction: a sociocultural linguistic approach. Discourse Studies, 7(4-5), 586-614.

Cover, R., \& Doak, S. (2015). Identity offline and online. International Encyclopedia of the Social \& Behavioral Sciences ( $2^{\text {nd }}$ ed., pp. 547-553). Elsevier. https://doi.org/10.1016/B9780-08097086-8.95078-5

De Fina, A. and Georgakopoulou, A. (2012). Analyzing Narrative. Discourse and Sociolinguistic Perspectives. Cambridge: CUP.

Edwards, D. (1998). The relevant thing about her: social identity categories in use. In C. Antaki \& S. Widdicombe (eds.), Identities in talk, (pp.15-33). London: Sage.

Edwards, J. (2009) Language and Identity. An Introduction. Cambridge, New York, etc.: CUP.

Housley, W. \& Fitzgerald, R. (2015). Introduction to membership categorisation analysis. In R. Fitzgerald \& W. Housley (eds.), Advances in membership categorisation analysis, (pp. 1-24). London: Sage.

James, W. (1892). Psychology. New York: Henry Holt.

Larsen-Freeman, D. (2010). Having and Doing: Learning from a Complexity Theory Perspective. In P. Seedhouse, S. Walsh, \& C. Jenks (eds.). Conceptualising 'learning in applied linguistics, (pp. 52-68). New York: Palgrave.

Le Page, R., \& Tabouret-Keller, A. (1985). Acts of identity: Creole-based approaches to language and ethnicity. Cambridge: CUP.

Markus, H. (1977). Self-schemata and processing information about the self. Journal of Personality and Social Psychology, 35, 63-78.

Markus, H., Crane, M., Berstein, S., \& Siladi, M. (1982). Self-schemas and gender. Journal of Personality and Social Psychology, 42, 38-50.

Orsatti, J., \& Riemer, K. (2015). Identity-making: A multimodal approach for researching identity in Social Media. In European Conference on Information Systems 2015 (pp. 1-18). Münster, 
Germany. Access date 20/05/2019. https://balsa.man.poznan.pl/indico/event/44/material/ paper/0? contribId $=152$

Oyserman, D. (2007). Social identity and selfregulation. In A. W. Kruglanski \& E. T. Higgins (eds.), Social psychology: Handbook of basic principles, (2nd ed., pp. 432-453). New York: Guilford Press.

Oyserman, D., Elmore, K., \& Smith, G. (2012). Self, self-concept, and identity. In M. Leary \& J. P. Tangney (eds.), Handbook of self and identity, (pp. 69-104). New York: The Guilford Press.

Pennycook, A. (2007). Global Englishes and transcultural flows. London, New York: Routledge.

Roccas, S., Brewer, M. B. (2002). Social identity complexity. Personality and Social Psychology Review, 6, 88-106.

Rosch, E. (1978). Principles of categorisation. In E. Rosch and B. Lloyd, (eds.). Cognition and Categorisation, (27-48). Hillsdale, N.J.: Erlbaum Associates.

Sacks, H. (1992). Lectures on Conversation. Oxford: Blackwell.

Sacks, H. (1984). Notes on methodology. In J. M. Atkinson and J. Heritage (eds.). Structures of Social Action: Studies in Conversational Analysis, (pp. 21-27). Cambridge: Cambridge University Press.

Sacks, H. (1974). An analysis of the course of a joke's telling in conversation. In R. Bauman and J. Sherzer (eds.), Explorations in the Ethnography of Speaking (pp. 337-353). Cambridge University Press.

Sacks, H. (1972a). On the analyzability of stories by children. In J. Gumperz and D. Hymes (eds.), Directions in Sociolinguistics: the Ethnography of Communication, (pp. 325-345). New York: Holt, Rinehart and Winston.

Sacks, H. (1972b). An initial investigation of the usability of conversational data for doing sociology. In D. Sudnow (ed.), Studies in Social Interaction, (pp. 31-74). New York: Free Press.

Schatzki, T.R. (1996). Social Practices: a Wittgensteinian Approach to Human Activity and the Social. Cambridge: Cambridge University.

Sternberg, R. J., and Horvath, J. A. (1995). A prototype view of expert teaching. Educational Researcher, 24(6), 9-17.

Stokoe, E. H. (2003). Doing gender, doing categorisation: Recent developments in language and gender research. International Sociolinguistics, 2(1) Online at: http://www.crisaps.org/ newsletter/backissue/stokoe_back.pdf

Tajfel, H. (1981). Human Groups and Social Categories. Cambridge: Cambridge University Press. Tajfel, H. (1982). Social Identity and Intergroup Relations. Cambridge: Cambridge University Press.

Tajfel, H. and Turner, J. C. (1979). An integrative theory of intergroup conflict. In W. G. Austin and S. Worchel (eds.), The Social Psychology of Intergroup Relations, (pp. 33-47). Monterey, CA: Brooks/Cole.

Tajfel, H. and Turner, J. (1986). The social identity theory of intergroup behaviour. In S. Worchel and W. G. Austin (eds.), Psychology of intergroup relations. Chicago: Nelson.

Widdicombe, S. (1998). "But you don't class yourself". The interactional management of category membership and non-membership. Ch. Antaki. and S. Widdicombe (eds.), Identities in Talk, (pp. 52-70). London: Sage. 